\title{
Report of first dengue outbreak in Aizawl, Mizoram, northeast India: Epidemiological and entomological surveillance and observations
}

\author{
Lalfakzuala Pautu*, Zorammuana, Pachuau Lalmalsawma, Zoramthara \\ Integrated Disease Surveillance Programme (IDSP) \& State Vector Borne Disease Control Programme (SVBDCP), Directorate of \\ Health Services, Aizawl 796ooI, Mizoram, India
}

\begin{abstract}
Outbreaks of dengue disease have been reported from many parts of India including northeastern States. There were reports of dengue disease outbreaks from Moreh town in Manipur during 2007-2008 and from Pasighat in Arunachal Pradesh during 2012 from northeast India. The first outbreak of dengue-like fever in Mizoram was reported on $30^{\text {th }}$ August from Tuikual North ' $C$ ' Mual, Aizawl, followed by consecutive outbreaks at 10 localities between August and December 2016 within Aizawl city. In these localities, epidemiological and entomological studies were conducted to identify the disease and its vector. Blood serums were collected from the patients for the serological confirmation and Aedes mosquitoes (adults and larvae) were collected for vector identification and confirmation. There were 580 (NS1=384, $\lg \mathrm{M}=196)$ patients confirmed with the disease from 11 localities in Aizawl and Ae. aegypti were identified as a potential vector species. There was no predilection towards sexes and all age group are affected with a median age 30. Parameters of entomological study revealed high density of vector mosquito in the study areas. Public health actions pertaining to the prevention and control of the disease were implemented. As dengue is included among the notifiable diseases in India, government authorities should strengthen manpower, case management and laboratory support, and regularly organizing interactive co-ordination meetings at all levels to sensitize public through IEC and awareness programmes as well as source reduction of Aedes mosquito breeding.
\end{abstract}

Key words: Ae. aegypti, Dengue, DENV, entomological study, epidemiological study, localities outbreaks, Surveillance.

\section{Received 14 March 2017}

Accepted 5 June 2017

*For correspondence $\bowtie$ : fakaento@gmail.com

\section{Introduction}

The word "dengue" is derived from the Swahili phrase, Ka-dinga pepo, literally meaning 'cramp-like seizure'. It was first referred as 'water poison' associated with flying insects in a
Chinese medical encyclopedia from the Jin Dynasty (265-420 CE). The first recognized dengue epidemic occurred in Asia, Africa and North America in the 1780s. Benjamin Rush coined the term 'backbone fever' because of the symptoms of myalgia and arthralgia. ${ }^{1}$ Dengue is currently 
regarded as the most important mosquito-borne human viral disease in terms of both the number of cases and the number of death and it is also considered a major global threat by World Health Organization (WHO) ${ }^{2}$ Dengue incidence has increases by 30 folds in the last 50 years with more than 100 countries reporting the presence of the disease. ${ }^{3}$ There has been differences in opinion of dengue global distribution from $30 \%{ }^{4}$ to $54.7 \%{ }^{4}$ of the world population $(2.05-3.75$ billions) ${ }^{4,5}$ According to WHO 2009 classification, dengue is divided into two groups:- uncomplicated (DF) and severe (DHF/DSS) ${ }^{2}$ In India, the first epidemic of clinical dengue-like illness was recorded in Madras in 1780 and the first virologically-proved epidemics of DF occurred in Kolkata and eastern coast of India in 1963-1964..$^{6-8}$ The DHF started spreading in various parts of India since 1988.9-11 The first major widespread of epidemics of DHF/DSS occurred in India in 1996 involving areas around Delhi ${ }^{12}$ and Lucknow $^{13}$ and then it spread to all over the country. ${ }^{14}$

Dengue viruses (DENV) are single-stranded RNA viruses belonging to genus Flavivirus of the family Flaviviridae and have four distinct serotypes (DEN 1-4) that are further classified into genotypes and clades phylogenetically. ${ }^{15}$ The mixing infections of serotypes/genotypes are known to effect severity complications of dengue ${ }^{16}$ and minor genetical changes in arboviruses RNA may result in increase in transmission and severity resulting in epidemic situations. ${ }^{17}$ From the mid-1990s, epidemics of dengue in India have become progressively larger and more frequent, usually starting in urban areas and quickly spreading to neighbouring regions. India became endemic for both DF and DHF/DSS as transmission become sustained during the inter-epidemic periods in large parts of the country. ${ }^{18,19}$ Dengue disease is transmitted to human by Aedes (stegomyia) aegypti (Linnaeus) and Aedes (Stegomiya) albopictus (Skuse) mosquito species. $^{20}$

The first dengue-like fever outbreak was reported on 31 August 2016, to the State Vector Borne Disease Control Programme (SVBDCP) Directorate of Health Services, Mizoram from the resident of Tuikual North, 'C' Mual area within Aizawl city. Expert team consisting of medical doctors and entomologist from SVBDCP and Integrated Disease Surveillance Programme (IDSP) rushed to the locality to investigate the situations and other related issues. Following to this outbreak there were several reports of dengue outbreaks from other localities within Aizawl city. There was a report on 13 October 2016 from Electric Veng and on 18 October 2016 from Ramhlun Sport Complex localities. Another outbreaks report were received from Chhinga Veng, Ramthar, Bethlehem Vengthlang, Zemabawk, Armed Veng, Dinthar, Saron, and Chanmari localities within the month of November and December 2016. In all these outbreak localities epidemiological and entomological studies were conducted by the team.

\section{Study area and population}

Aizawl, the capital of Mizoram, India is a hilly city lies within $23.36^{\circ} \mathrm{N}$ and $92.8^{\circ} \mathrm{E}$ and having a temperature ranges from $20-30^{\circ} \mathrm{C}$ in summer and $11-21^{\circ} \mathrm{Cin}$ winter. It receives $215 \mathrm{~cm}$ of rainfall annually and features a humid subtropical climate but very rainy and relative humidity is $46 \%$. According to 2011 census Aizawl has a total population of $2,93,416 .{ }^{21}$

This study was conducted to confirm dengue disease outbreak serologically and entomologically and to implement public health actions for the control and prevention of further spreading of the disease.

\section{Materials and Methods}

\section{Epidemiological study}

In all outbreak localities surveyed, patients were found in clusters and all were exhibiting same symptoms like fever with rash, muscles and joints pain, abdominal pain, epistaxis, vomitting etc. which resembles the symptoms of dengue. Almost all of the patients have no history of travelling outside the state. For the serological confirmation of dengue disease, blood 
sample were collected from outbreak localities and sent to Sentinel site at Civil Hospital Aizawl to confirm with ELISA Reader. Continuous epidemiological surveillance and vigilance were implemented in these localities.

\section{Entomological study}

Entomological investigation as per National Vector Borne Disease Control Programme (NVBDCP) guidelines to identify the vector mosquito of dengue and to determine the density of vector population in all the outbreak localities was conducted by trained Entomologist. The species of vector mosquito was identified and the sampling technique for vector surveillance utilised in these areas were for both adults and larvae. For adult survey, per man hour density (PMHD) was utilised which indicates the number of adult vector mosquitoes collected within an hour. For larval survey the following indices were used:

1. House index $(\mathrm{HI})=$

No. of positive houses X 100

No. of houses searched

2. Container index (CI) =

No. of positive containers X 100

Number of containers searched

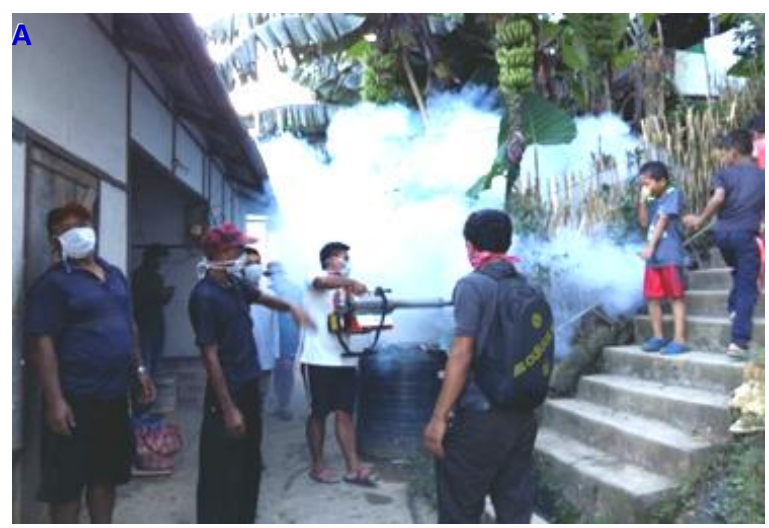

3. Breteau index $(\mathrm{BI})=$

No. of positive containers X 100

No. of houses searched

4.Pupae index $(\mathrm{PI})=$

No. of pupae observed X 100

Number of houses searched

Study of pupae index is very important during the on-going transmission period because, the pupae hatch out as an adult within a day or two and will feed on human blood meal and thus increase chances of transmission to enhance the on-going outbreak, if no interventions for vector control measures to cut-off the transmission were operated. Adults and larvae of mosquitoes collected in the outbreak localities were reared in the laboratory for species identification.

\section{Public health actions}

Even before the serological confirmation of the disease, public health actions were initiated in outbreak localities because the epidemiological and entomological findings supported the disease outbreak was dengue disease. Actions taken were (Figure 1):

1. Public awareness campaigns through public meeting and print media.

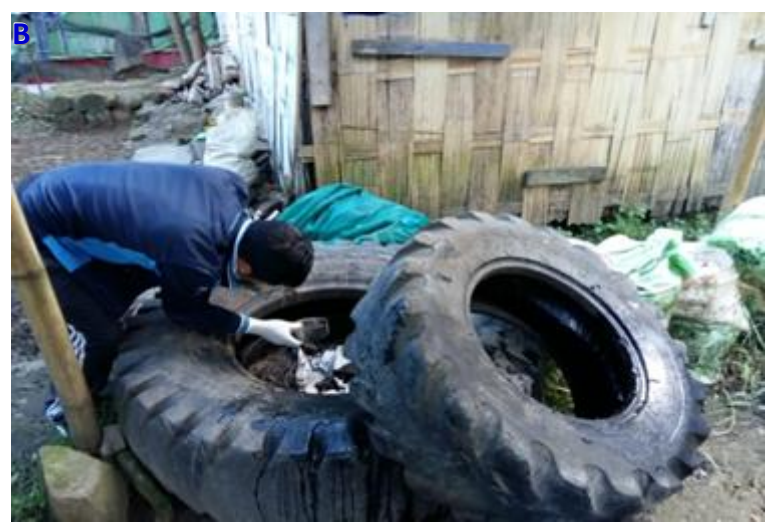

Figure 1 | Vector-mosquito control. A. Space spray/fogging; B. Source reduction. 
2. Voluntary works for source reduction under the supervision of the expert team.

3. House-to-house visit and serum collection by medical personnel.

4. Thermal fogging/space spray in the affected areas and its surroundings.

\section{Results}

Prior to this dengue outbreak in Aizawl, there were several sporadic cases of dengue recorded each year. The first outbreak was identified and confirmed at Tuikual North, 'C' Mual and it was followed by another 10 consecutive outbreaks in different localities of Aizawl and one outbreak reported from Kolasib town during 2016. Due to timely introduction of interventions for the vector control, all these outbreaks were under controlled and subsided with a fortunate zero mortality case.

\section{Epidemiological observation}

In 2012, sentinel sites for dengue diagnosis was established at Civil hospital Aizawl and Civil Hospital Lunglei and were equipped with ELISA readers. Several confirmed cases are recorded each year with increased number of cases each year but the cases were found sporadic and dispersed from 2012 to 2015 (Table 1). But, during 2016, starting from the month of August there were several dengue outbreaks reported from different areas within Aizawl city. There were 580 confirmed cases, (cases on January and February 2017 were included for comparative purpose and to show outbreaks were subsided in these months (Table 2), out of which $384=$ $66.20 \%$ patients confirmed with NS1 antigen and $196=33.80 \%$ confirmed with IgM antibodies which shows the effectiveness of surveillance system and awareness of the disease to the mass (Figure 2). There was no predilection in both sexes as the percentages of males (49.48\%) and females (50.25\%) are almost equal, and all age groups are affected by this disease in the outbreaks (Table 3). The oldest patient recorded was 87-year-old male and the youngest patient was 2-year-old female. There was no record of patient less than 1 year. Age group of 21-30 has maximum number of cases, the median age was 30. There were 11 outbreak localities within Aizawl city which contributes $59.66 \%$ of dengue cases in altogether from the total cases during the year 2016 (Table 4). Serotypes of DENV in this outbreak could not be identified due to various constraints.

Table 1 | Dengue in Aizawl, confirmed cases (2012-2016).

\begin{tabular}{lccccccc} 
Year & 2012 & 2013 & 2014 & 2015 & 2016 & Total & Death \\
No. of cases & 6 & 7 & 19 & 43 & 580 & 655 & 0 \\
\hline
\end{tabular}

Table 2 | Dengue cases confirmed with NS1 and IgM (Jan 2016 - Feb 2017).

\begin{tabular}{lccccccccccccccc}
\hline $\begin{array}{l}\text { Months } \\
\text { Jan }\end{array}$ & Feb & Mar & Apr & May & Jun & Jul & Aug & Sep & Oct & Nov & Dec & $\begin{array}{c}\text { Jan } \\
\text { 2017 }\end{array}$ & $\begin{array}{c}\text { Feb } \\
\mathbf{2 0 1 7}\end{array}$ & Total \\
$\begin{array}{l}\text { Sample } \\
\text { tested }\end{array}$ & 0 & 32 & 16 & 22 & 23 & 22 & 35 & 35 & 139 & 215 & 570 & 314 & 72 & 48 & 1543 \\
\hline $\begin{array}{l}\text { Positive } \\
\text { NS1 }\end{array}$ & 0 & 0 & 0 & 0 & 0 & 0 & 0 & 0 & 19 & 130 & 174 & 61 & 9 & 1 & 394 \\
\hline IgM & 0 & 1 & 0 & 0 & 0 & 0 & 0 & 0 & 30 & 20 & 90 & 55 & 5 & 5 & 206 \\
\hline $\begin{array}{l}\text { Total } \\
\text { confirm- } \\
\text { ed cases }\end{array}$ & 0 & 1 & 0 & 0 & 0 & 0 & 0 & 0 & 49 & 150 & 264 & 116 & 14 & 6 & 600 \\
\end{tabular}


Table 3 | Distribution of cases among age groups.

\begin{tabular}{|cc|}
\hline Age groups & Number of cases \\
\hline $0-10$ & 36 \\
\hline $11-20$ & 137 \\
\hline $21-30$ & 141 \\
\hline $41-40$ & 102 \\
\hline $51-60$ & 60 \\
\hline $61-70$ & 59 \\
\hline $71 \&$ above & 31 \\
\hline Total & 14 \\
\hline
\end{tabular}

Median age $=30 ;$ mode $=22 ;$ females $=293(50.52 \%)$; males $=287(49.48 \%) ;$ oldest $=87 \mathrm{yrs} \mathrm{M}$; youngest $=2$ yrs F.

Table 4 | Dengue case distribution at outbreak localities in Aizawl.

\begin{tabular}{clc} 
Sl.no & \multicolumn{1}{c}{ Localities } & No. of cases \\
\hline 1 & Chhinga Veng & 49 \\
\hline 2 & Tuikual North & 43 \\
\hline 3 & Ramhlun sport complex & 41 \\
\hline 4 & Electric Veng & 37 \\
\hline 5 & Ramthar Veng & 32 \\
\hline 6 & Bethlehem Vengthlang & 30 \\
\hline 7 & Zemabawk & 29 \\
\hline 8 & Arm Veng & 28 \\
\hline 9 & Dinthar Veng & 24 \\
\hline 10 & Saron Veng & 17 \\
\hline 11 & Chanmari & 16 \\
\hline & Total & 346 \\
\hline
\end{tabular}

\section{Entomological observations}

All Aedes mosquito collected, adults and larvae are identified as Aedes (Stegomyia) aegypti (Linnaeus) species and no Aedes albopictus species were collected in the surveys although Ae. albopictus are found in abundant in rural and forested areas in Mizoram. The vector indices for both adult and larvae are given in the Table 5 . Breeding sites of Ae. aegypti includes discarded tyres, flower pots, barrels, tanks, drums, plastic bags, small pots, tins, cans, buckets etc. The average per man hour density was 10.2, PMHD more than 2 is a high risk for an outbreak. Average house index was $48.4 \%$ and container index was $43.1 \%$, where $\mathrm{HI}$ and $\mathrm{CI}$ more than $10 \%$ is a high risk. The average breteau index and pupae index were 124.4 and 115 respectively, BI and PI more than 50 is alarming. Maximum number of cases and vector mosquitoes are found in lowlying areas which are congested and lying adjacent to water courses and streams.

\section{Discussion}

In the northeast region of India, serological survey conducted during 1963 revealed the prevalence of dengue in the Lohit district of AP and Darrang district of Assam. ${ }^{22,23}$ Another report of dengue (DENV) in Assam and Nagaland appeared during the nineties.23,24,25 During 20092011, a study by Dutta and Mahanta ${ }^{23}$ reported 143 laboratory-confirmed cases belonging to Assam, Nagaland, Manipur and Arunachal Pradesh. There was reports of dengue disease outbreaks from Moreh town, Chandel district of Manipur during 2007-2008,,5 and from Pasighat, East Siang district of Arunachal Pradesh during July-August $2012 .{ }^{26}$ In this study, outbreaks in Aizawl were reported from August to December, this could be due to prolonged monsoon rain. Usually dengue outbreaks are started in urban areas and gradually invaded rural areas. ${ }^{18,19}$ This epidemiological pattern was also observed in Mizoram; the first outbreaks were restricted within Aizawl city from August to December 2016 but, in the latter part of December 2016, there was a report of dengue outbreak at Kolasib town under Kolasib district which is $87 \mathrm{kms}$ away from Aizawl, 38 confirmed cases were recorded.

In majority of dengue outbreak studies in the past, males outnumbered females in DENV positivity and occurrence of more cases of DENV in adults than in children is observed ${ }^{27}$ However, in an outbreak investigation in Narsinghpur, it was noted that both sexes were equally affected..$^{28}$ The present study also found that there 
Table 5 | Vector indices for adults and larvae in outbreak localities.

\begin{tabular}{llccccc} 
SI. & & \multicolumn{3}{c}{ Localities } & \multicolumn{3}{c}{ Houses and containers searched in outbreak localities } \\
\cline { 3 - 7 } No & & PMHD & $\mathrm{HI}$ & $\mathrm{Cl}$ & $\mathrm{BI}$ & $\mathrm{PI}$ \\
\hline 1 & Chhinga Veng & 18 & 43.1 & 36.2 & 186 & 177.2 \\
\hline 2 & Tuikual North & 18.5 & 48.1 & 54.9 & 241.1 & 83.3 \\
\hline 3 & Ramhlun sport complex & 10 & 46.8 & 40.8 & 125 & 156.2 \\
\hline 4 & Electric Veng & 8 & 34.7 & 29.1 & 91.3 & 130.4 \\
\hline 5 & Ramthar Veng & 14 & 36 & 38.8 & 70 & 108 \\
\hline 6 & Bethlehem Vengthlang & 8.4 & 73.8 & 45.8 & 84.6 & 110.7 \\
\hline 7 & Zemabawk & 4.5 & 67.5 & 54.9 & 153.7 & 103.7 \\
\hline 8 & Armed Veng & 6.6 & 41.7 & 50.3 & 114.7 & 83.4 \\
\hline 9 & Dinthar Veng & 8.5 & 48.4 & 43.8 & 130.3 & 109.1 \\
\hline 10 & Saron Veng & 10.2 & 50 & 49.5 & 96.2 & 116.6 \\
\hline 11 & Chanmari & 6 & 43.3 & 30.6 & 76.6 & 86.6 \\
\hline
\end{tabular}

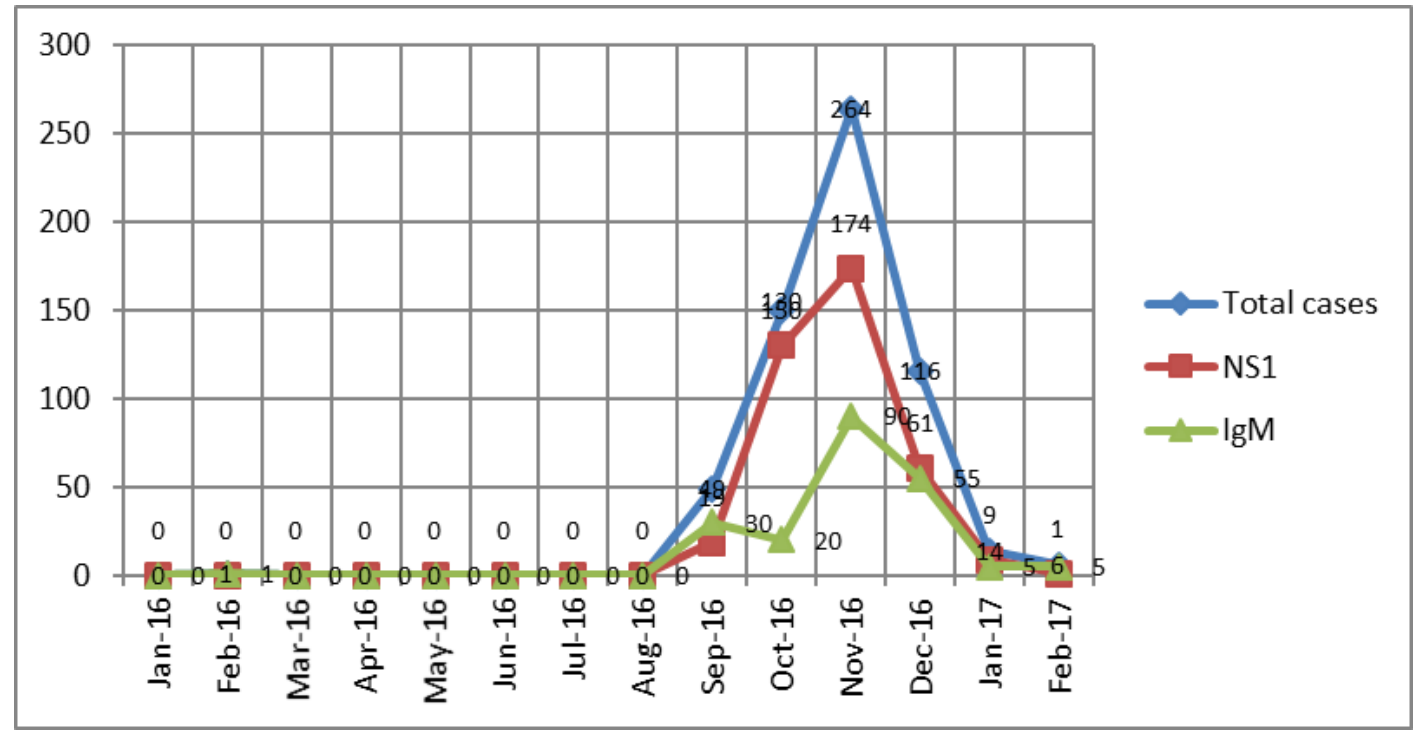

Figure 2 | Graph to represent dengue positive cases with NS1 and IgM.

is no predilection of sexes (female to male ratio of 1:0.97) and younger age groups are more affected than older age groups with the median age of 30 .

Studies have demonstrated that elevated adult and larval indices contributes the upsurge of cases. ${ }^{18,28,29}$ All the indices for both adult and larva during the entomological studies conducted revealed high density of vector mosquito in the study areas which is the indication to show the necessity of continuous operation of vector control measures such as, chemical control, biological control and source reduction to minimise the breeding habitat of the vector.

The potential vector species identified in this study, Ae. Aegypti is the most common vector of DENV in India followed by Ae. albopictus. Larval indices indicates that Ae. aegypti is well established in urban and peri-urban areas and is beginning to displace Ae. albopictus as almost all 
the water-holding containers facilitates the breeding of Ae. aegypti. ${ }^{30}$ Urbanization, transport developments, constructions and alteration of environment etc. immensely enhance chances of dengue outbreaks. ${ }^{31}$

In the absence of efficient vaccine for dengue, certain measures like personal protection, vector control and public awareness to the disease and vector's bionomics with timely and accurate laboratory diagnosis are the only way to combat dengue outbreaks. As dengue is included among the notifiable diseases in India, ${ }^{32}$ government authorities should strengthen manpowers, case management and laboratory support, and regularly organizing interactive coordination meetings at all levels to sensitize public through Information, Education and Communication (IEC) and awareness programmes as well as source reduction of Aedes mosquito breeding.

\section{Acknowledgement}

The authors would like to express their sincere thanks to senior entomologists and scientists of National Centre for Disease Control (NCDC), National Vector Borne Disease Control Programme (NVBDCP) for their technical support; Lalrinliana Fanai, Secretary \& Commissioner of Health \& Family Welfare Department, Govt. of Mizoram for his support; Principal Director, Health and Family Welfare Department and Director of Health Services for providing technical and financial supports; Dr. H.C Thangkima, State Programme Officer NVBDCP for his guidance and valuable technical and financial supports.

\section{References}

I. Anonymous. (2009). Dengue Fever. www.globalmedicine.nl/index.php/dengue-fever. (25 October 20I5).

2. World Health organization. (2009). Dengue guidelines for diagnosis, treatment, prevention and control. h t t p : / / w h q li b d o c. w h o. i n t / publications/2009/9789241547871.eng.pdf. ( os March
2016).

3. World Health Organization. (2016). Dengue and severe dengue, Fact sheet No.II7. http://www.who.int/ mediacentre/factsheets/fsir7/en/. (I6 May 2016).

4. Simmons, C., Farrar, J., Chau, N. \& Wills, B. (20I2). Dengue. New England Journal of Medicine 366, 1423I432.

5. Beatty, M., Letson, W., Edgil, D. \& Margolis, H. (2007). Estimating the total world population at risk for locally acquired dengue infection. American Journal of Tropical Medicine and Hygiene 77, 170-257.

6. Sarkar, J., Chatterjee, S. \& Chakravarti, S. (1964). Haemorrhagic fever in Calcutta: some epidemiological observations. Indian Journal of Medical Research 52, 651-690.

7. Chatterjee, S., Chakravarti, S., Mitra, A. \& Sarkar, J. (1965). Virological investigation of cases with neurological complications during the outbreak of haemorrhagic fever in Calcutta. Journal of Indian Medical Association 45, 314-316.

8. Carey, D., Myers, R., Reuben, R. \& Rodrigues, F. (1966). Studies on dengue in Vellore, South India. American Journal of Tropical Medicine and Hygiene is, 580-587.

9. Kabra, S., Verma, I., Arora, N., Jain, Y. \& Kalra, V. (1992). Dengue haemorrhagic fever in children in Delhi. Bulletin of World Health Organization 70, I05-108.

ı. Bhattacharjee, N., Mukherjee, K., Chakravarti, S., Mukherjee, M., De, P. \& Sengupta, M. (1990). Dengue haemorrhagic fever (DHF) outbreak in Calcutta. Journal of Communicable Disieses 25, IO-I4.

II. Cherian, T., Ponnuraj, E., Kuruvilla, T., Kirubakaran, C., John, T. \& Raghupathy, P. (1994). An epidemic of dengue haemorrhagic fever \& dengue shock syndrome in and around Vellore. Indian Journal of Medical Research 100, 5I-56.

I2. Dar, L., Broor, S., Sengupta, S., Xess, I. \& Seth, P. (1999). The first major outbreak of dengue haemorrhagic fever in Delhi, India. Emerging Infectious Diseases 5, 589-590.

13. Agarwal, R., Kapoor, S., Nagar, R., Misra, A., Tandon, R. \& Mathur, A. (1999). A clinical study of the patients of dengue haemorrhagic fever during the epidemic of 1996 at Lucknow, India. Southeast Asian Journal of Tropical Medicine and Public Health 30, 735-740. 
14. Shah, I., Deshpande, G. \& Tardeja, P. (2004). Outbreak of dengue in Mumbai and predictive markers for dengue shock syndrome. Journal of Tropical Pediatric so, 30I-305.

I5. Zhang, C., Mammen M, Jr., Chinawirotpisan, P., Klungthong, C. \& Rodpradit, P. (2005). Clade replacements in dengue virus serotypes $\mathrm{I}$ and 3 are associated with changing serotype prevalence. Journal of Virology 79, $15123-15130$.

I6. Fried, J., Gibbons, R., Kalayanarooj, S., Thomas, S., Srikiatkhachorn, A. \& Yoon, I. (2010). Serotype specific differences in the risk of dengue haemorrhagic fever: An analysis of data collected in Bangkok, Thailand from 1994 to 2006. Public Library Of Sciences (PloS) Neglected Tropical Diseases 4, 617.

17. Gubler, D. (1988). Dengue; Epidemiology of arthropodborne viral disease. In T.P Monath (ed), 23, pp. 223-26o.

18. Anonymous. (2014). Guidelines for Clinical management of dengue Fever. Dengue Haemorrhagic Fever and dengue Shock Syndrome. National Vector Borne disease control Programme (NVBDCP), 22, Sham Nath Magh, Delhi-IIoos4,

19. http://www.nvbdcp.gov.in/doc/clinical\% 2oguidelines.pdf (22 June 2016).

20. Chaturvedi, U. \& Nagar, R. (2008). Dengue and dengue haemorrhagic fever: Indian perspective. Journal of Biosciences 33, 429-44I.

2I. Gupta, N., Srivastava, S., Jain, A. \& Chaturvedi, U. (2012). Dengue in India. Indian Journal of Medical Research 136, 373-390.

22. Anonymous. (2013). Geographical information of Aizawl.

23. https://en.m.wikipedia.org/wiki/Aizawl (28 November 2016).

24. Rodrigues, F. \& Dandawate, C. (1977). Arthropod borne viruses in North-eastern India: a serological survey of Arunachal Pradesh and northern Assam. Indian Journal of Medical Research 65, 453-465.
25. Dutta, P. \& Mahanta, J. (2006). Potential vectors of dengue and the profile of dengue in the North-eastern region of India: an epidemiological perspective. Dengue Bulletin 30, 234-242.

26. Barua, H. \& Mahanta, J. (1996). Serological evidence of Den-2 activity in Assam and Nagaland. Journal of Communicable Diseases 28, 56-58.

27. Sankari, T., Hoti, S., Singh, T. \& Shanmugavel, J. (2012). Outbreak of dengue serotype-2 (DENV-2) of Cambodian origin in Manipur, India-association with mateorological factor. Indian Journal of Medical Research $\mathbf{1 3 6 , 6 4 9 - 6 5 5}$.

28. Khan, A., Dutta, P., Topno, R., Soni, M. \& Mahanta, J. (20I4). Dengue outbreak in a hilly state of Arunachal Pradesh in Northeast India. Science World Journal 20I4, I-6.

29. Chakravarti, A., Arora, R. \& Luxemburger, C. (20I2). Fifty years of dengue in India. Transactions of the Royal Society Tropical Medicine and Hygiene 106, 273-82.

3o. Barde, P., Kori, B., Shukla, M., Bharti, P. \& Chand, G. (20I5). Maiden outbreaks of dengue virus I genotype III in rural central India. Epidemiol Infect, 143, 412-418.

3I. Anonymous. (2016). Manual on integrated vector management India. National Vector Borne Disease Control Programme (NVBDCP), 22, Sham Nath Magh, DelhiIIo054, India. http://www.nvbdcp.gov.in/Doc/IVMro March 2016.pdf (I4 September 2016).

32. Sharma, K., Angel, B., Singh, H., Purohit, A. \& Joshi, V. (2008). Entomological studies for vector surveillance and prevention of dengue in arid and semi-arid districts of Rajasthan, India. Journal of Vector Borne Diseases 45, I24-I32.

33. Fulmali, P., Walimbe, A. \& Mahadev, P. (2008). Spread, establishment \& prevalence of dengue vector Aedes aegypti (L) in Konkan region, Maharastra, India. Indian Journal of Medical Research 127, 589-60I.

34. Anonymous. (2016). List of notifiable diseases in India.

35. http://www.ihatepsm.com/blog/list-notifiable-diseasesindia (I7 January 20I7). 